\title{
Strain-hardening and suppression of shear-banding in rejuvenated bulk metallic glass
}

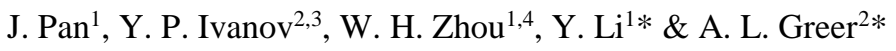 \\ ${ }^{1}$ Shenyang National Laboratory for Materials Science, Institute of Metal Research, Chinese Academy of \\ Sciences, Shenyang, China. \\ ${ }^{2}$ Department of Materials Science \& Metallurgy, University of Cambridge, Cambridge, UK. \\ ${ }^{3}$ School of Natural Sciences, Far Eastern Federal University, Vladivostok, Russia \\ ${ }^{4}$ School of Materials Science and Engineering, University of Science and Technology of China, Hefei, China. \\ *e-mail: liyi@imr.ac.cn; alg13@cam.ac.uk
}

Strain-hardening (the increase of flow stress with plastic strain) is the most important phenomenon in the mechanical behaviour of engineering alloys because it ensures that flow is delocalized, enhances tensile ductility and inhibits catastrophic mechanical failure $^{1,2}$. Metallic glasses (MGs) lack the crystallinity of conventional engineering alloys, and some of their properties—such as higher yield stress and elastic strain limit ${ }^{3}$ - are greatly improved relative to their crystalline counterparts. MGs can have high fracture toughness and have the highest known 'damage tolerance' (defined as the product of yield stress and fracture toughness) ${ }^{4}$ among all structural materials. However, the promise of MGs for structural applications is largely thwarted by the fact that they show strain-softening, instead of strain-hardening; this leads to extreme localization of plastic flow in shear bands, and is associated with early catastrophic failure in tension. Although rejuvenation of an MG (raising its energy to values that are typical of glass formation at a higher cooling rate) lowers its yield stress, which might enable strain-hardening ${ }^{5}$, it is unclear whether sufficient rejuvenation can be achieved in bulk samples while retaining their glassy structure. Here we show that plastic deformation under triaxial compression at room temperature can rejuvenate bulk MG samples sufficiently to enable strain-hardening through a mechanism that has not been previously observed in the metallic state. This transformed behaviour suppresses shear-banding in bulk samples in normal uniaxial (tensile or compressive) tests, 
prevents catastrophic failure and leads to higher ultimate flow stress. Furthermore, the rejuvenated MGs are stable at room temperature and show exceptionally efficient strain-hardening, greatly increasing their potential use in structural applications.

Plastic flow in crystalline metals is mediated by glide of dislocations. Well annealed pure metals can have very low yield stress $\sigma_{y}$; as flow continues, dislocations proliferate and increasingly impede each other's glide, leading to strain-hardening, in which the flow stress $\sigma_{\mathrm{f}}$ increases with the plastic strain ${ }^{6}$. By contrast, MGs have intrinsically high $\sigma_{\mathrm{y}}$, and yielding at room temperature is followed by softening ${ }^{7}$, leading to shear bands ${ }^{8}$ and inhomogeneous deformation. The shear bands produce undesirable surface markings, weaken the sample and ultimately evolve into cracks ${ }^{8}$.

Similarly to the Griffith criterion for crack propagation, there is a critical MG crosssection for the development of shear bands ${ }^{9}$. For cross-sections smaller than $100 \mathrm{~nm}$, shearbanding is suppressed, flow is homogeneous, the plastic strain $\left(\varepsilon_{\mathrm{p}}\right)$ can reach $25 \%$, and the MG shows strain-hardening ${ }^{10}$. As shear-banding is associated with offsets, it can also be suppressed by mechanical constraint, as demonstrated in notched rods subjected to tension ${ }^{11}$; the hydrostatic tension increases atomic mobility, and the resulting structural relaxation leads to hardening. Unlike earlier studies (Extended Data Table 1), here we aim to suppress shearbanding without limitations in size or mechanical constraint - that is, in bulk single-phase monolithic glasses subjected to simple uniaxial loading. Strain-hardening is seen in MGmatrix composites when flow induces transformation of the dispersed crystalline phase (Extended Data Table 2).

MGs are made by cooling the liquid sufficiently rapidly to avoid crystallization. A given composition forms a range of glassy states that depend on the cooling rate. Slower cooling gives states of higher density, higher $\sigma_{\mathrm{y}}$ and reduced plasticity; such states can also be produced by annealing to induce structural relaxation (ageing). We are instead interested in rejuvenation to states of higher energy (and correspondingly higher fictive temperature, $T_{\text {fict }}$ ), which are obtainable by faster cooling, irradiation or thermomechanical processing 5 . Such states can, for example, show an abrupt toughening transition as $T_{\text {fict }}$ is increased ${ }^{12}$. A rejuvenated MG with reduced $\sigma_{\mathrm{y}}$ might show hardening, instead of softening, as flow progresses, and in this regime there would be no localization of shear (Fig. 1c in ref. ${ }^{5}$ ). 
Uniaxial compression of a notched 4-mm-diameter MG rod (Fig. 1a) rejuvenates a central zone, as demonstrated by a map of the reduced hardness ${ }^{13}$. In contrast to an earlier study of a MG sample under tension ${ }^{11}$, the central zone is deformed under triaxial compression, suppressing relaxation. Our rejuvenated samples are 3-mm-long and 1.5-mmdiameter rods machined from such zones. As-cast $\mathrm{Zr}_{64.13} \mathrm{Cu}_{15.75} \mathrm{Ni}_{10.12} \mathrm{Al}_{10} \mathrm{MG}$ has a microhardness of $\mathrm{Hv}_{\text {as-cast }}=495 \pm 5 \mathrm{kgf} \mathrm{mm}^{-2}$ (kilograms force per square millimetre, mean \pm s.d., $n \geq 10$ ) whereas rejuvenated samples have a microhardness of $\mathrm{Hv}=421 \pm 9 \mathrm{kgf} \mathrm{mm}^{-2}$ at their centre (normalized hardness $\mathrm{Hv} / \mathrm{Hv}_{\text {as-cast }}=0.85$ ). The heat of relaxation $\Delta H_{\text {rel }}$ of the ascast MG, $0.49 \pm 0.04 \mathrm{~kJ} \mathrm{~mol}^{-1}$, increases to $1.08 \pm 0.06 \mathrm{~kJ} \mathrm{~mol}^{-1}$ upon rejuvenation. Using standard estimations ${ }^{13}$, this would correspond to cooling at $\sim 10^{6} \mathrm{~K} \mathrm{~s}^{-1}$ - three to four orders of magnitude higher than the possible cooling rate for a 1.5-mm-diameter cast rod. Although an MG produced by cooling the liquid at $10^{6} \mathrm{~K} \mathrm{~s}^{-1}$ would match our rejuvenated samples in terms of $\Delta H_{\text {rel }}$, it would not necessarily do so in its other properties. Extended Data Table 3 lists the properties of the samples used in this study.

A rejuvenated rod is uniaxially compressed to chosen strains at room temperature, and is then unloaded and reloaded (Fig. 1b). On reloading, plastic flow resumes on a continuous stress-strain curve: $\sigma_{\mathrm{y}}$ is higher on successive loadings, indicating strain-hardening. Initial yielding is at $\sim 1.8 \%$ elastic strain and $\sigma_{\mathrm{y}} \approx 1.35 \mathrm{GPa}$ - lower than the corresponding values for as-cast glass $(\sim 2.3 \%, 1.70 \mathrm{GPa})$. Compressive plastic flow is stable up to a total strain of at least $10 \%$.

With strain-hardening, there would be no cause for shear-banding: the stress-strain curves would be smooth, as is observed (Fig. 1b) up to $\varepsilon_{\mathrm{p}} \approx 3 \%$. For continuous loading (without intermediate unloading), smooth flow is retained in some samples beyond $\varepsilon_{\mathrm{p}} \approx 7 \%$, owing to either a lack or proliferation of shear bands. When serrations appear, the stress drops are small. The inset in Fig. 1b shows a close-up comparison of yielding in rejuvenated and as-cast samples (true stress versus true strain). For the as-cast sample, the yielding onset is sharp and the flow is serrated almost immediately. The stress drops, corresponding to shear-banding, are 40-50 MPa, an order of magnitude larger than in the rejuvenated glass at high $\varepsilon_{\mathrm{p}}$. In the rejuvenated sample, the true $\sigma_{\mathrm{f}}$ reaches $1.7 \mathrm{GPa}$.

The effects of rejuvenation are confirmed by observations of the sample surfaces. An as-cast sample shows failure at a total strain of $\varepsilon_{\mathrm{t}} \approx 3.8 \%$ (Fig. 2a), and shear-banding (arrows) appears even far from the fracture plane. A rejuvenated sample (Fig. 2b) after compression to $\varepsilon_{\mathrm{p}}=1.0 \%, \varepsilon_{\mathrm{t}}=3.2 \%$ (Fig. $2 \mathrm{c}, \mathrm{d}$ ) shows no evidence of shear-banding. At 
$\varepsilon_{\mathrm{p}}=3.5 \%$ there is one dominant and many secondary shear bands, and the sample shows bulging (Fig. 2e). At $\varepsilon_{\mathrm{p}}=19 \%$ (Fig. 2f), the sample bulging contrasts with early failure of the as-cast sample of the same initial dimensions. Similar rejuvenation-induced strain-hardening, suppression of shear-banding, and enhanced plasticity are confirmed in a second Zr-based MG (Extended Data Figs. 1, 2).

Changes in the glassy state associated with strain-hardening can be quantified using the exothermic heat of relaxation $\Delta H_{\text {rel }}$ (the heat released on heating to the glass transition (Fig. 3a), which is correlated with hardness) as a function of the plastic strain applied on the as-cast and rejuvenated samples (Fig. 3b). The $\Delta H_{\text {rel }}$ value of the rejuvenated sample is reduced to $0.65 \mathrm{~kJ} \mathrm{~mol}^{-1}$ at $\varepsilon_{\mathrm{p}}=3.5 \%$, indicating that plastic flow induces structural relaxation (Fig. 3c). At this point, the normalized hardness in the rejuvenated MG is increased to 0.94 . When $\varepsilon_{\mathrm{p}}=22.5 \%, \Delta H_{\text {rel }}$ increases to $0.79 \mathrm{~kJ} \mathrm{~mol}^{-1}$ and the normalized hardness decreases to 0.91 but they do not revert to the values of the undeformed rejuvenated MG. The hardness trend (Fig. 3b) is similar to that of the true $\sigma_{\mathrm{f}}$ (Fig. 1b, inset), but the fit is not quantitative, possibly because the hardness is influenced by residual stresses.

As expected, higher hardness is associated with more relaxed states of lower $\Delta H_{\text {rel }}$; the observed strain-hardening is thus associated with structural relaxation, which can be seen as a spring-back from rejuvenation (arrowed in Fig. 3b,c). By contrast, plastic deformation of an as-cast sample induces rejuvenation (lower hardness, higher energy). The changes in the as-cast sample are smaller because the plastic flow is inhomogeneous (in shear bands) ${ }^{13}$-not homogeneous, as in the rejuvenated sample.

In tension, the rejuvenated glass shows strain-hardening that is similar to that observed during compression but somewhat faster (Extended Data Fig. 3). Shear-banding starts earlier than in compression, at $\varepsilon_{\mathrm{p}} \approx 0.57 \%$, and failure is observed at $\varepsilon_{\mathrm{p}} \approx 0.68 \%$.

High-resolution transmission electron microscopy (Fig. 4a) shows that a rejuvenated sample is fully amorphous, chemically homogeneous, and without any nanocrystallinity (Extended Data Fig. 4). Rejuvenation shifts the first halo in the electron diffraction pattern to lower value of $q$ (the magnitude of the scattering vector) (Fig. 4b), which is associated with greater average atomic volume ${ }^{14}$. Simply interpreted, the shift would correspond to a density decrease of $1.0-1.5 \%$, which is large for an $\mathrm{MG}$, although density changes as large as $+1 \%$ (by annealing) ${ }^{15}$ and $-0.5 \%$ (by thermal cycling) ${ }^{16}$ have been reported. The second halo in the 
radial distribution function (Extended Data Fig. 5) shows changes upon rejuvenation that suggest the generation of more loosely packed configurations ${ }^{17}$.

In a sample deformed after rejuvenation, the first halo shifts back towards higher $q$ (Fig. 4b). The structural changes indicated by the position of the first halo $q_{1}$ correlate well with the changes in $\Delta H_{\text {rel }}$ and $\mathrm{Hv}$ (Fig. 3b-d), supporting the link between strain-hardening and structural relaxation.

The initial rates of hardening, $\mathrm{d}($ stress $) / \mathrm{d} \varepsilon_{\mathrm{p}}$, are as high as $59 \mathrm{GPa}$, much higher than those of crystalline alloys (Extended Data Fig. 6), showing that the hardening mechanism is very efficient. However, the extent of strain-hardening is limited by the initial energy of the glass, and the hardening capacity is soon exhausted $\left(\varepsilon_{\mathrm{p}} \approx 4 \%\right.$ in compression, $\varepsilon_{\mathrm{p}} \approx 0.7 \%$ in tension). As the hardening continues, the glass reverts towards its as-cast state, and ultimately shear-banding resumes at higher strains. The uniformity of local flow stress (a consequence of strain-hardening) continues to be beneficial, weakening the stress serrations and enabling relatively homogeneous flow to continue to much larger strains and somewhat higher stresses than for an as-cast sample.

Under given deformation conditions, an MG can approach a steady-state energy ${ }^{5}$. For as-cast glasses, the energy rises during this process with $1-10 \%$ of the work done being stored in the sample, as is typical for crystalline metals. However, if the initial glass has a high enough energy (arrow in Fig. 3c), then under deformation that energy must fall towards the steady state. We observed such behaviour in bulk (millimetre-scale) MG samples of more than one composition, and showed that the energy reduction (relaxation) induces strainhardening and suppression of shear-banding. This is achieved without the triaxial constraint that was used to obtain strain-hardening in earlier work ${ }^{11}$. Here the required rejuvenation is achieved with small $\varepsilon_{\mathrm{p}}$ under sufficient hydrostatic compression, and this can be extended to larger volumes and is not restricted to particular MG compositions. Future focus should shift from shear-band engineering ${ }^{8}$ (hindering propagation and promoting proliferation of shear bands) towards their elimination. Our results confirm that the mechanical properties of glasses - for example, oxides ${ }^{18}$ — can be transformed by suitable processing.

Eighty-five years after Taylor's analysis ${ }^{6}$, we have a novel mechanism inducing strain-hardening in the metallic state that is based on a reduction in energy (and in effective defect density) instead of an increase. The fact that rejuvenation of a bulk MG can transform its mechanical behaviour to achieve strain-hardening and suppression of shear-banding, 
without the glass being structurally unstable (to relaxation or crystallization) at room temperature, underpins the potential of using MGs as structural materials.

1. Cottrell, A. H. The Mechanical Properties of Matter Sect. 9.6, 284-291 (Krieger, 1981).

2. Dieter, G. E. Mechanical Metallurgy Chap. 9, 237-272 (McGraw-Hill, 1961).

3. Ashby, M. F. \& Greer, A. L. Metallic glasses as structural materials. Scripta Mater. 54, 321-326 (2006).

4. Demetriou, M. D. et al. A damage-tolerant glass. Nature Mater. 10, 123-128 (2011).

5. Sun, Y. H., Concustell, A. \& Greer, A. L. Thermomechanical processing of metallic glasses: extending the range of the glassy state. Nature Rev. Mater. 1, 16039 (2016).

6. Taylor, G. I. The mechanism of plastic deformation of crystals. Part I.- Theoretical. Proc. Royal Soc. A 145, 362-387 (1934).

7. Spaepen, F. A microscopic mechanism for steady state inhomogeneous flow in metallic glasses. Acta Metall. 25, 407-415 (1977).

8. Greer, A. L., Cheng, Y. Q. \& Ma, E. Shear bands in metallic glasses. Mater. Sci. Eng. Rep. 74, 71-132 (2013).

9. Volkert, C. A., Donohue, A. \& Spaepen, F. Effect of sample size on deformation in amorphous metals. J. Appl. Phys. 103, 083539 (2008).

10. Jang, D. \& Greer, J. R. Transition from a strong-yet-brittle to a stronger-and-ductile state by size reduction of metallic glasses. Nature Mater. 9, 215-219 (2010).

11. Wang, Z. T., Pan, J., Li, Y. \& Schuh, C. A. Densification and strain hardening of a metallic glass under tension at room temperature. Phys. Rev. Lett. 111, 135504 (2013).

12. Ketkaew, J. et al. Mechanical glass transition revealed by the fracture toughness of metallic glasses. Nature Comm. 9, 3271 (2018).

13. Pan, J. et al. Extreme rejuvenation and softening in a bulk metallic glass. Nature Comm. 9, 560 (2018).

14. Ma, D., Stoica, A. D. \& Wang, X.-L. Power-law scaling and fractal nature of mediumrange order in metallic glasses. Nature Mater. 8, 30-34 (2009).

15. Wang, W. H. et al. Stability of ZrTiCuNiBe bulk metallic glass upon isothermal annealing near the glass transition temperature. J. Mater. Res. 17, 1385-1389 (2002).

16. Guo, W., Saida, J., Zhao, M., Lü, S. \& Wu, S. Thermal rejuvenation of an Mg-based metallic glass. Metall. Mater. Trans. A 50A, 1125-1129 (2019).

17. Pan, S. P., Qin, J. Y., Wang, W. M. \& Gu, T. K. Origin of splitting of the second peak in the pair-distribution function for metallic glasses. Phys. Rev. B 84, 092201 (2011). 
18. Januchta, K. et al. Breaking the limit of micro-ductility in oxide glasses. Adv. Sci. 1901281 (2019). 


\section{FIGURES}
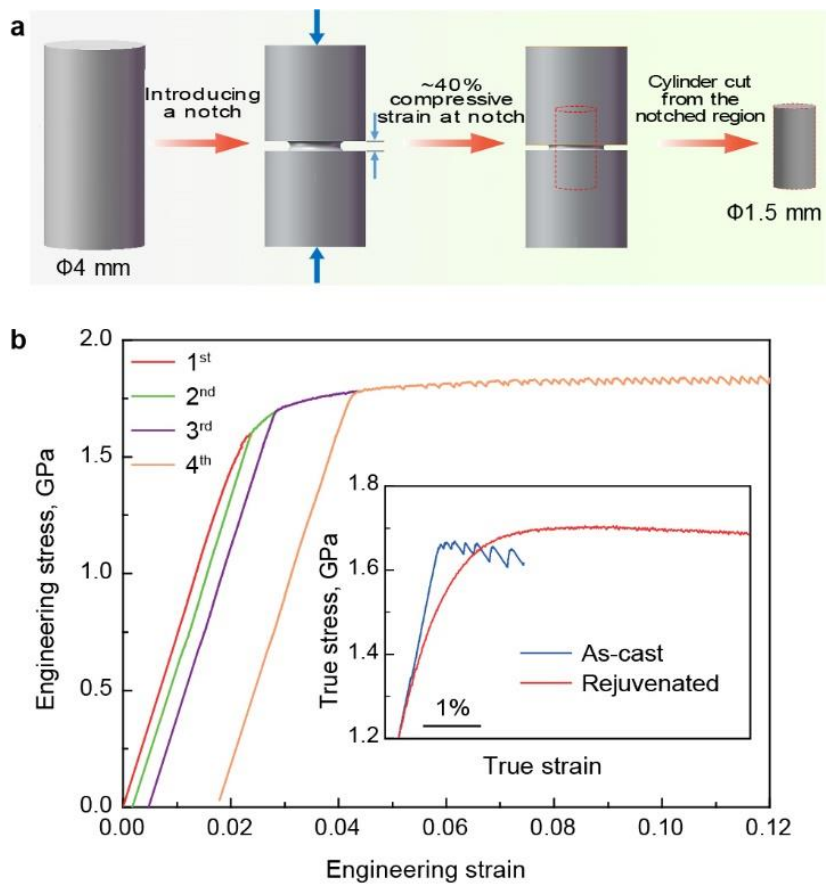

Fig. 1 | Rejuvenation and deformation of an MG. a, A 4-mm-diameter rod of $\mathrm{Zr}_{64.13} \mathrm{Cu}_{15.75} \mathrm{Ni}_{10.12} \mathrm{Al}_{10}$ bulk MG is machined to have a circumferential notch. Uniaxial compression induces plastic deformation, reducing the notch width by $40 \%$. This processing produces a highly rejuvenated region within the rod, from which a $1.5-\mathrm{mm}$-diameter, 3 -mmlong glass rod is machined. b, Four engineering stress-strain curves for uniaxial compression, corresponding to three unloading-reloading cycles of one sample rejuvenated as in a. Inset, comparison of true stress-true strain curves of a rejuvenated sample and a 2-mm-diameter ascast rod of the same composition. The rejuvenated glass shows extensive homogeneous flow (without serrations) and strain-hardening (manifest in the characteristic unloading-reloading curves). 


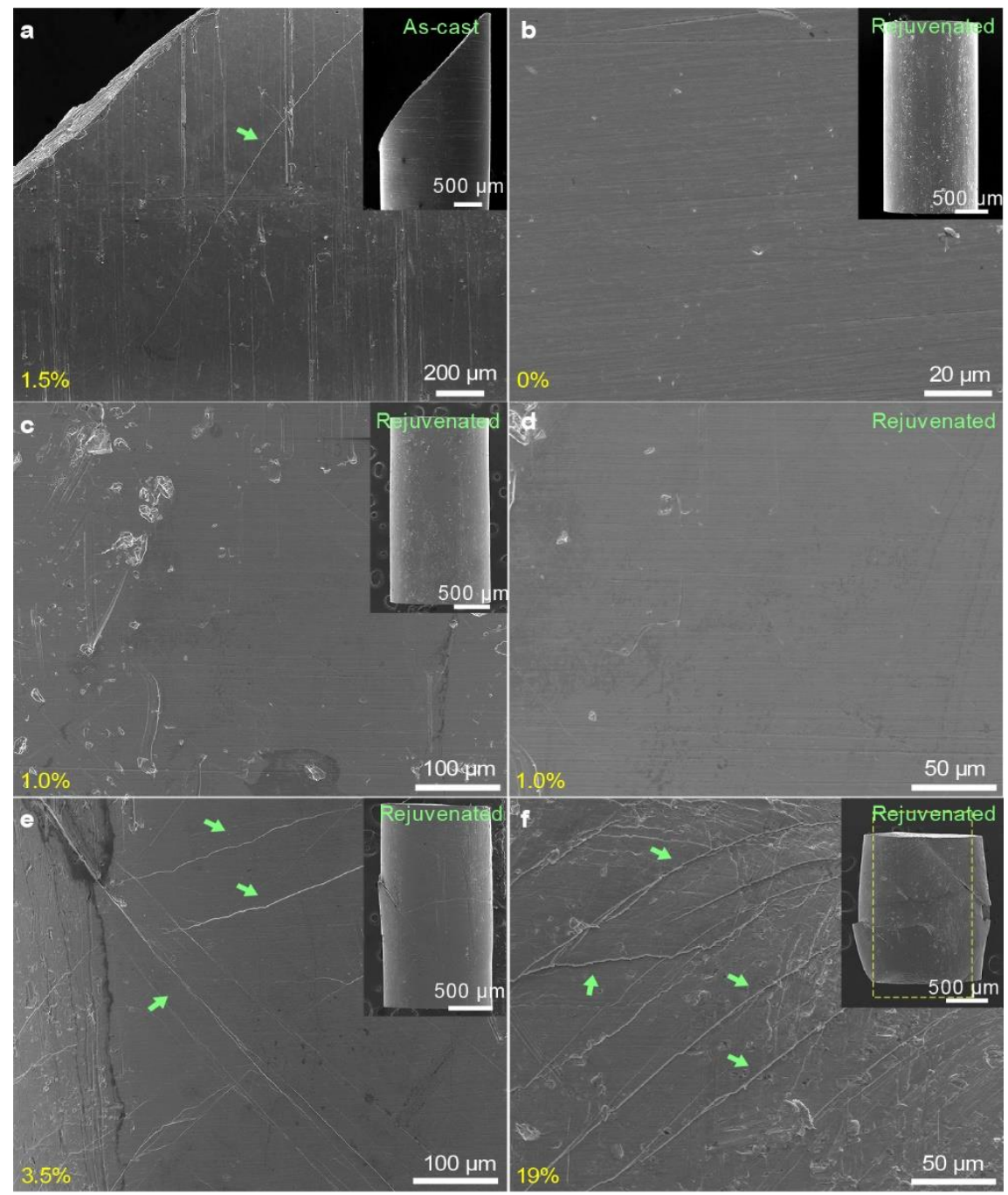

Fig. 2 | The onset of inhomogeneous flow (shear-banding) leads to surface steps on samples subjected to uniaxial compression. Scanning electron micrographs and the corresponding values of plastic strain $\left(\varepsilon_{\mathrm{p}}\right)$. a, An as-cast sample of the Zr-based glass fails at $\varepsilon_{\mathrm{p}} \approx 1.5 \%$ and shows a dominant shear band when subsidiary shear bands already exist (arrow). b-f, A rejuvenated sample shows no shear bands initially (b) or at $\varepsilon_{\mathrm{p}} \approx 1.0 \%(\mathbf{c}, \mathbf{d})$, but shear bands are evident at $\varepsilon_{\mathrm{p}} \approx 3.5 \%(\mathbf{e})$, and at $\varepsilon_{\mathrm{p}} \approx 19 \%$ the sample shows clear bulging and a high density of shear bands (f). 

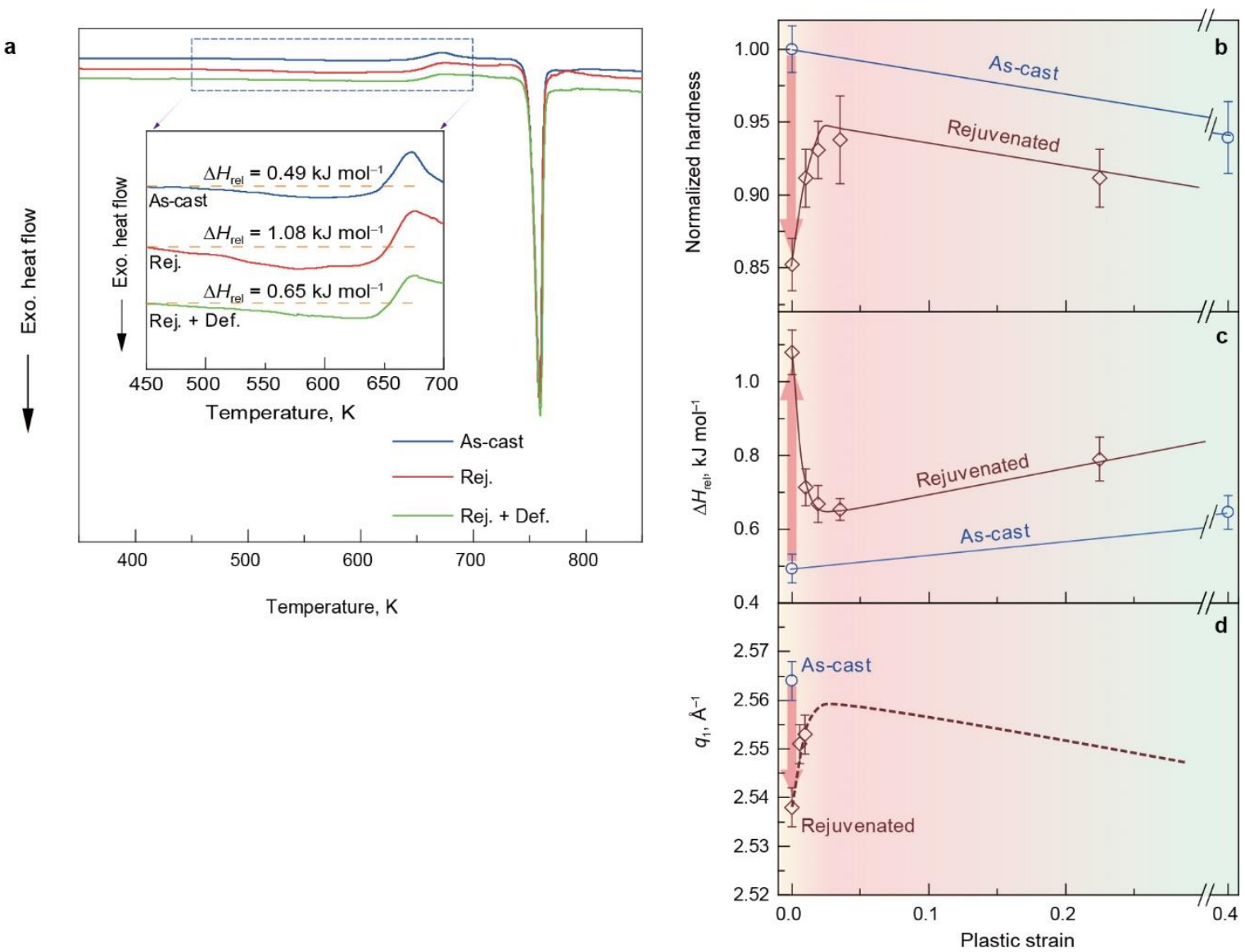

Fig. 3 | Induced changes in the MG state. a, Differential scanning calorimetry traces measured on heating of $\mathrm{Zr}_{64.13} \mathrm{Cu}_{15.75} \mathrm{Ni}_{10.12} \mathrm{Al}_{10} \mathrm{MG}$ samples at $20 \mathrm{~K} \mathrm{~min}^{-1}$ : as-cast (blue), rejuvenated (red), and rejuvenated and then deformed under uniaxial compression to selected strains (green). The inset shows a close-up of the relaxation exotherm and the glass transition. The dashed horizontal lines in the inset show the baseline with respect to which the heat of relaxation $\Delta H_{\text {rel }}$ is measured. Details about the samples are provided in Extended Data Table 3. b-d, Normalized microhardness $\mathrm{Hv} / \mathrm{Hv}_{\text {as-cast }}$ (where $\mathrm{Hv}_{\text {as-cast }}=495 \mathrm{kgf} \mathrm{mm}{ }^{-2}$ ) (b), heat of relaxation $\Delta H_{\text {rel }}(\mathbf{c})$, and the position of the main diffraction halo $q_{1}$ (d; see Fig. 4b) of rejuvenated samples (diamonds) as a function of the compressive plastic strain applied. The arrows show the property changes induced by the prior rejuvenation. Values of as-cast samples (circles; from ref. ${ }^{13}$ ) are shown for comparison. The error bars show the standard deviation for the measurements. 

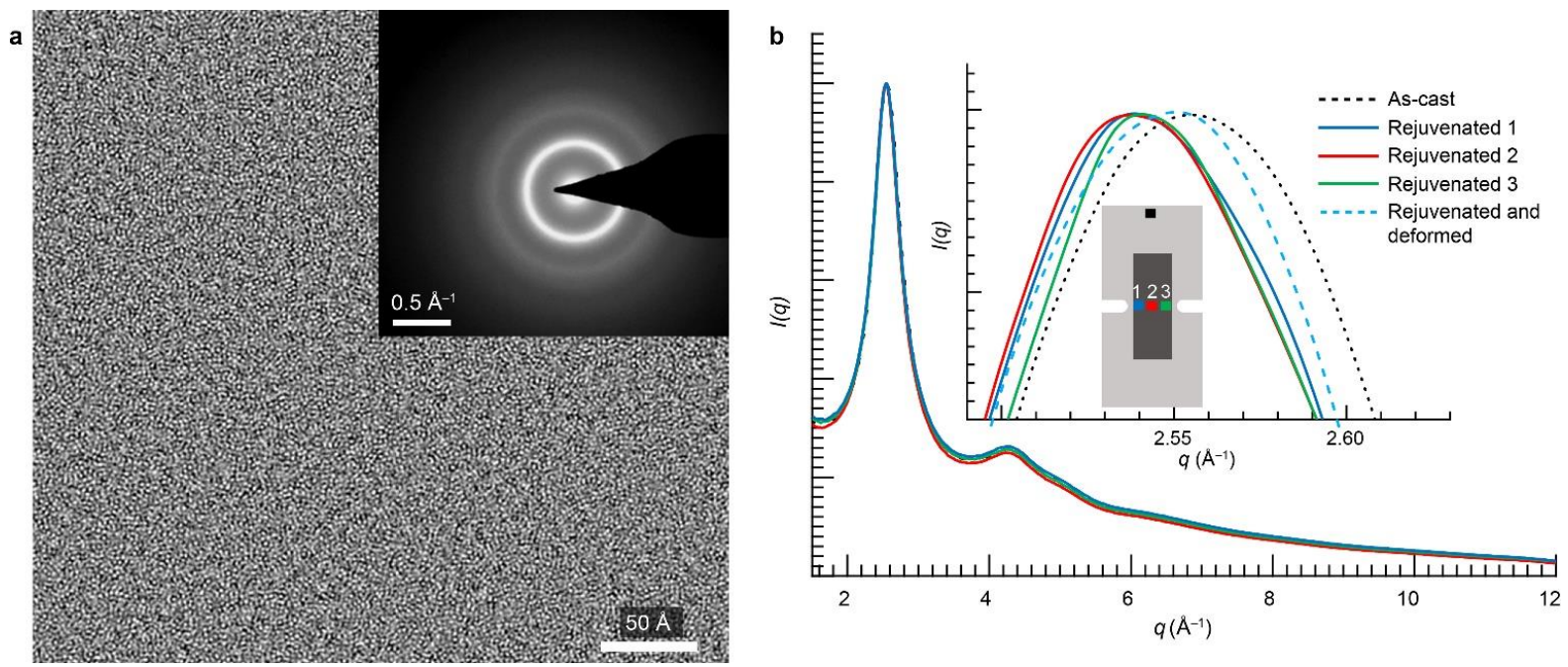

Fig. 4 | Transmission electron microscopy of as-cast and rejuvenated MG. a, Highresolution transmission electron micrograph and selected-area electron diffraction (SAED) pattern (inset) of a rejuvenated sample. b, Azimuthally averaged scattered intensity, $I(q)$, as a function of the scattering-vector magnitude $q$, of the SAED pattern. Inset: close-up of the position $q_{1}$ of the main halo; the colours of the curves relate to the colours on the sketch of the rod cross-section, showing the regions (1-3 marked in the sketch) studied by the transmission electron microscopy. The dark grey rectangle in the centre of the rod corresponds to the cylinder that is machined out to obtain the rejuvenated samples for mechanical testing. All the samples from the rejuvenated cross-section show a shift of $q_{1}$ to lower values, indicating a reduction in the density of the glass. When a rejuvenated sample is subsequently deformed by uniaxial compression (to $\varepsilon_{\mathrm{p}}=-0.57 \%$ ), $q_{1}$ shifts back to a higher value. The measured values of $q_{1}$ are listed in Extended Data Table 3. 


\section{METHODS}

\section{Preparation of bulk-metallic-glass specimens}

Alloys with nominal composition $\mathrm{Zr}_{64.13} \mathrm{Cu}_{15.75} \mathrm{Ni}_{10.12} \mathrm{Al}_{10}$ (atomic percentage) were prepared by arc-melting mixtures of high-purity (greater than 99.9\%) metals in a Ti-gettered highpurity argon atmosphere. Cylindrical samples with diameters of $1.5 \mathrm{~mm}, 2 \mathrm{~mm}, 4 \mathrm{~mm}$ and $5 \mathrm{~mm}$ were cast in copper moulds. Rejuvenation of the cast samples was achieved via the steps shown in Fig. 1a. In each 4-mm-diameter rod, a circumferential notch $1.0 \mathrm{~mm}$ deep and $0.45 \mathrm{~mm}$ wide was produced by gentle grinding in a custom-made machine, followed by fine polishing (as described previously ${ }^{19,20}$ ). Then, the notched specimens were compressed along the cylindrical axis until, through plastic flow, the width of the notch was reduced by $\sim 40 \%$. As previously shown ${ }^{13}$, this compression induces rejuvenation throughout a central region extending $2 \mathrm{~mm}$ above and below the notch. Each rejuvenated rod used in the compression tests was obtained by machining a cylinder $\sim 1.5 \mathrm{~mm}$ in diameter and $\sim 3 \mathrm{~mm}$ in height from the central region. (This is the region shown in green in figure $2 \mathrm{c}$ in ref. ${ }^{13}$, corresponding to a reduction in microhardness of $\sim 15 \%$.)

For tensile testing, 5-mm-diameter rods with a circumferential notch $1.5 \mathrm{~mm}$ deep and $0.45 \mathrm{~mm}$ wide were produced, and were then compressed along the cylindrical axis until the width of the notch was reduced by $\sim 45 \%$. The central zones of these samples (rejuvenated by the constrained compression) were extracted and mechanically polished into dog-boneshaped tensile specimens that had a gauge length of $\sim 2 \mathrm{~mm}$ and cross-section of $\sim 1.00 \times 0.35 \mathrm{~mm}^{2}$. The amorphicity of the as-cast and rejuvenated specimens was verified by $\mathrm{X}$-ray diffraction (D2 PHASER, Bruker Corp.) using $\mathrm{Cu} \mathrm{K} \alpha$ radiation at $40 \mathrm{kV}$.

No systematic studies were conducted on the stability of the rejuvenated specimens. After three months at room temperature, however, there was no discernible change in their properties (most closely monitored for microhardness).

\section{Mechanical testing}

All tests were conducted at room temperature at a strain rate of $1 \times 10^{-4} \mathrm{~s}^{-1}$. Compression tests on 1.5-mm-diameter rejuvenated specimens were conducted using a Shimadzu AG-I or AG-X tensile testing machine; as-cast 2-mm-diameter specimens were studied for comparison. Before testing, the ends of the specimens were polished carefully to be parallel. Quasi-static uniaxial tensile tests were performed using an INSTRON-5848 micro-tester system. The fracture surfaces and the cylindrical surfaces of the samples after mechanical 
testing were examined by scanning electron microscopy (Quanta 600 scanning electron microscope, FEI). Microhardness testing (Q10 A+ microhardness tester, Qness GmbH; Vickers indenter) of specimens before and after compression was conducted with a load of $50 \mathrm{~g}$ and dwell time of $15 \mathrm{~s}$.

\section{Thermal analysis}

The thermal response of the as-cast and rejuvenated specimens was investigated using differential scanning calorimetry (Q2000 differential scanning calorimeter, TA Instruments) at a heating rate of $20 \mathrm{~K} \mathrm{~min}^{-1}$ in a flow of argon. After first heating to $873 \mathrm{~K}$ (completely crystallizing the specimen), a second run under identical conditions was used to determine the baseline for each measurement.

\section{Structural characterization}

Thin foils for transmission electron microscopy (TEM) were prepared with a final thickness of 30-50 nm by focused ion-beam milling using a Helios Nanolab focused-ion-beam scanning electron microscope. The bulk-metallic-glass rod was sectioned as shown in the inset of Fig. 4b. The position marked by the black patch (far from the notched area) was used for the extraction of the specimens that represent the 'as-cast' condition; the central notched region was used for the extraction of the rejuvenated specimens. A thin protective layer of $\mathrm{Pt}$ $(200 \mathrm{~nm})$ was deposited over the target area using the electron beam before any ion-beam exposure. Subsequently, a standard in situ procedure was adopted to lift out the thin foil. Final polishing was conducted at a reduced voltage of $2 \mathrm{kV}$ to minimize the level of implanted gallium in the final specimen and the damage caused by gallium implantation.

TEM studies were carried out with a Tecnai Osiris (FEI) transmission electron microscope with a field-emission gun operated at $200 \mathrm{kV}$, equipped with Super-X windowless energy-dispersive X-ray (EDX) detector. The EDX experiments were performed in scanning TEM mode using a high-angle annular dark-field detector and a probe diameter of $\sim 0.2 \mathrm{~nm}$. SAED patterns and associated images were acquired with a Gatan US1000 charge-coupled device camera. The SAED aperture was $\sim 200 \mathrm{~nm}$, and the camera length was set to cover the high- $q$ range up to $12.2 \AA^{-1}$; the acquisition time was $1 \mathrm{~s}$. The magnitude of the scattering vector is defined as $q=(4 \pi / \lambda) \sin (\theta)$, where $\theta$ is the scattering half-angle and $\lambda$ is the electron wavelength. The radial distribution functions of the as-cast and rejuvenated samples were directly computed from the SAED patterns using the eRDF Analyser software ${ }^{21}$. For each specimen, the analysis was based on more than ten independently 
acquired SAED patterns. High-resolution TEM studies were carried out with a Titan G2 60300 microscope (FEI) equipped with a high-brightness field-emission gun and a Cs image corrector. The spatial resolution was estimated to be $\sim 0.08 \mathrm{~nm}$ at $300 \mathrm{kV}$.

\section{Data availability}

All data generated or analysed during this study are included in the published article and the Extended Data, and are available from the corresponding authors upon reasonable request.

19. Pan, J., Zhou, H. F., Wang, Z. T., Li, Y. \& Gao, H. J. Origin of anomalous inverse notch effect in bulk metallic glasses. J. Mech. Phys. Solids 84, 85-94 (2015).

20. Pan, J., Wang, Y. X. \& Li, Y. Ductile fracture in notched bulk metallic glasses. Acta Mater. 136, 126-133 (2017).

21. Shanmugam, J., Borisenko, K.B., Chou, Y.-J. \& Kirkland, A. I. eRDF Analyser: An interactive GUI for electron reduced density function analysis. SoftwareX 6, 185-192 (2017).

22. Guo, H. et al. Tensile ductility and necking of metallic glass. Nature Mater. 6, 735-739 (2007).

23. Tian, L. et al. Approaching the ideal elastic limit of metallic glasses. Nature Comm. 3, 609 (2012).

24. Tian, L., Shan, Z. W. \& Ma, E. Ductile necking behavior of nanoscale metallic glasses under uniaxial tension at room temperature. Acta Mater. 61, 4823-4830 (2013).

25. Chen, D. Z., Gu, X. W., An, Q., Goddard III, W. A. \& Greer, J. R. Ductility and work hardening in nano-sized metallic glasses. Appl. Phys. Lett. 106, 061903 (2015).

26. Qu, R. T., Liu, Z. Q., Wang, G. \& Zhang, Z. F. Progressive shear band propagation in metallic glasses under compression. Acta Mater. 91, 19-33 (2015).

27. Wang, J. G. et al. Hardening of shear band in metallic glass. Sci. Rep. 7, 7076 (2017).

28. Joo, S.-H. et al. Work-hardening induced tensile ductility of bulk metallic glasses via high-pressure torsion. Sci. Rep. 5, 9660 (2015).

29. Das, J. et al. "Work-hardenable" ductile bulk metallic glass. Phys. Rev. Lett. 94, 205501 (2005).

30. Yao, K. F. \& Zhang, C. Q. Fe-based bulk metallic glass with high plasticity. Appl. Phys. Lett. 90, 061901 (2007).

31. Xie, S., Tu, X. \& Kruzic, J. J. Inducing strain hardening in a Zr-based bulk metallic glass via cobalt mediated phase separations. J. Alloys Comp. 735, 1576-1581 (2018). 
32. Wang, T. et al. Two-step work-hardening and its gigantic toughening effect in Zr-based bulk metallic glasses. Scripta Mater. 150, 106-109 (2018).

33. Rashidi, R., Malekan, M. \& Gholamipour, R. Microstructure and mechanical properties of a $\mathrm{Cu}-\mathrm{Zr}$ based bulk metallic glass containing atomic scale chemical heterogeneities. Mater. Sci. Eng. A 729, 433-438 (2018).

34. Wu, Y., Xiao, Y., Chen, G., Liu, C. T. \& Lu, Z. Bulk metallic glass composites with transformation-mediated work-hardening and ductility. Adv. Mater. 22, 2770-2773 (2010).

35. Hofmann, D. C. Shape memory bulk metallic glass composites. Science 329, 1294 1295 (2010).

36. Pauly, S., Gorantla, S., Wang, G., Kühn, U. \& Eckert, J. Transformation-mediated ductility in CuZr-based bulk metallic glasses. Nature Mater. 9, 473-477 (2010).

37. Kim, C. P., Oh, Y. S., Lee, S. \& Kim, N. J. Realization of high tensile ductility in a bulk metallic glass composite by the utilization of deformation-induced martensitic transformation. Scripta Mater. 65, 304-307 (2011).

38. Song, K. K. et al. Triple yielding and deformation mechanisms in metastable $\mathrm{Cu}_{47.5} \mathrm{Zr}_{47.5} \mathrm{Al}_{5}$ composites. Acta Mater. 60, 6000-6012 (2012).

39. He, Q., Shang, J. K., Ma, E. \& Xu, J. Crack-resistance curve of a Zr-Ti-Cu-Al bulk metallic glass with extraordinary fracture toughness. Acta Mater. 60, 4940-4949 (2012).

40. Zhang, Z. F., Eckert, J. \& Schultz, L. Difference in compressive and tensile fracture mechanisms of $\mathrm{Zr}_{59} \mathrm{Cu}_{20} \mathrm{Al}_{10} \mathrm{Ni}_{8} \mathrm{Ti}_{3}$ bulk metallic glass. Acta Mater. 51, 1167-1179 (2003).

41. Bennett, C. H. Serially deposited amorphous aggregates of hard spheres. J. Appl. Phys. 43, 2727-2734 (1972).

42. Kelton, K. F. et al. First X-ray scattering studies on electrostatically levitated metallic liquids: Demonstrated influence of local icosahedral order on the nucleation barrier. Phys. Rev. Lett. 90, 195504 (2003).

43. Atlas of Stress-Strain Curves (ASM International, 2002) ISBN:9780871707390, p. 199.

Acknowledgements Y.L. and J.P. acknowledge support from National Natural Science Foundation of China under grant number 51871217 and from the Shenyang National Laboratory for Materials Science. A.L.G. and Yu.P.I. acknowledge support from the European Research Council under the European Union’s Horizon 2020 Research and 
Innovation programme (grant ERC-2015-AdG-695487: ExtendGlass). We thank A. Chuvilin for technical support of HRTEM (CIC, NanoGUNE, Spain), and J. Zhang for technical support and W. Huang for casting the rod samples (IMR, Shenyang, China).

Author contributions Y.L. and A.L.G. led the project and the writing of the paper. Rejuvenation of the MG samples and their characterization by microhardness testing, differential scanning calorimetry, uniaxial mechanical loading and surface observation by scanning electron microscopy were carried out by J.P. and W.H.Z. Transmission electron microscopy, including high-resolution TEM and the calculation of radial distribution functions, was performed by Y.P.I. All authors contributed to the interpretation and presentation of the results.

Competing interests: The authors declare no competing interests.

Correspondence and requests for materials should be addressed to Y.L. or A.L.G. 


\section{EXTENDED DATA FIGURES AND TABLES}
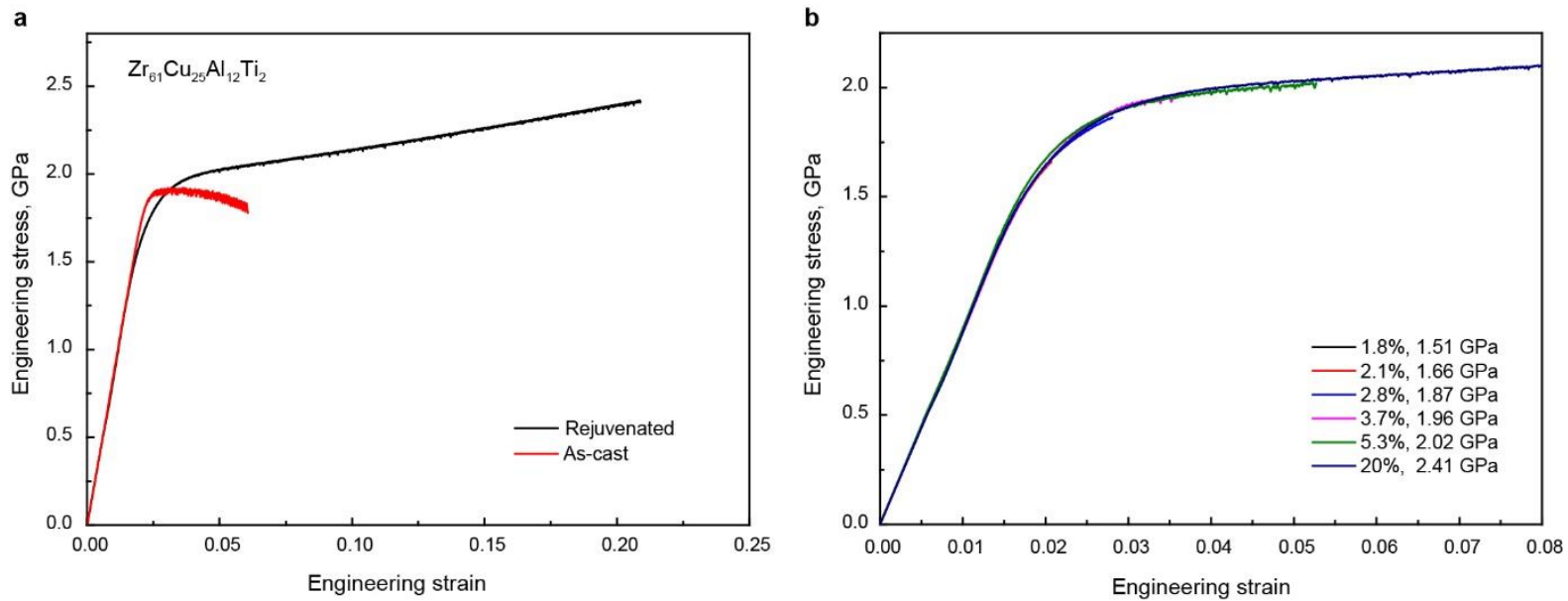

\section{Extended Data Fig. 1 | Uniaxial compression of $\mathrm{Zr}_{61} \mathrm{Cu}_{25} \mathrm{Al}_{12} \mathrm{Ti}_{2} \mathrm{MG}$ rods (1.5 mm}

diameter, 3.0 mm height). a, Engineering stress-strain curves of as-cast and rejuvenated rods. On increasing the stress, the yield stress $\sigma_{\mathrm{y}}$ is the point at which there is the first deviation from linearity. The curve of the rejuvenated rods shows a more gradual onset of yielding and a lower $\sigma_{\mathrm{y}}$. b, Superposed stress-strain curves for different rejuvenated rods. The compression tests were terminated at different points, and the total strain $\varepsilon_{\mathrm{t}}(1.8-20 \%)$ and flow stress $\sigma_{\mathrm{f}}(1.51-2.41 \mathrm{GPa})$ are listed in the key. The close correspondence of the curves shows the reproducibility of the results and the increase in $\sigma_{\mathrm{f}}$ is evidence for strain-hardening. In addition, the possibility of large strain without fracture and the very low amplitude of serrations (compared to an as-cast sample, see the inset in Fig. 1b) are clear. 


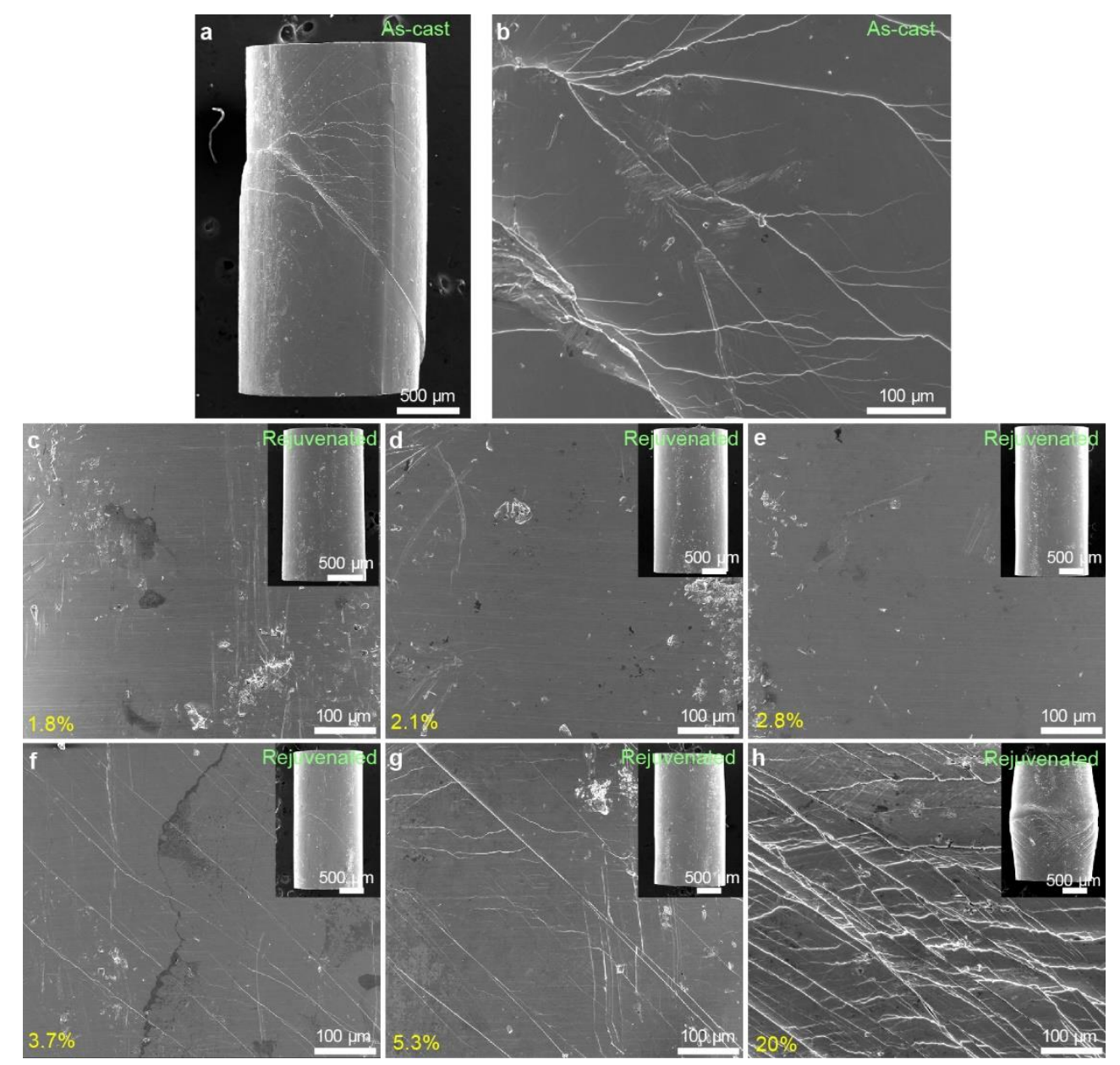

Extended Data Fig. 2 | Onset of inhomogeneous flow (shear-banding) in the compression of $\mathrm{Zr}_{61} \mathrm{Cu}_{25} \mathrm{Al}_{12} \mathrm{Ti}_{2} \mathrm{MG}$ rods. Scanning electron microscopy images of the samples used in the tests shown in Extended Data Fig. 1b, labelled with the corresponding values of total strain $\left(\varepsilon_{\mathrm{t}}\right)$. a, Shear-banding associated with the onset of plastic flow in the as-cast glass. $\mathbf{b}$, Close-up image of the shear bands shown in $\mathbf{a}$. $\mathbf{c}-\mathbf{h}$, Rods of rejuvenated MG (insets), tested to the total strains shown, and close-up images of the surfaces (main images). The onset of shear-banding is at $\varepsilon_{\mathrm{t}}=2.8-3.7 \%$. For finely spaced shear bands, extensive, relatively uniform flow and bulging of the sample can be seen $(\mathbf{h})$. 

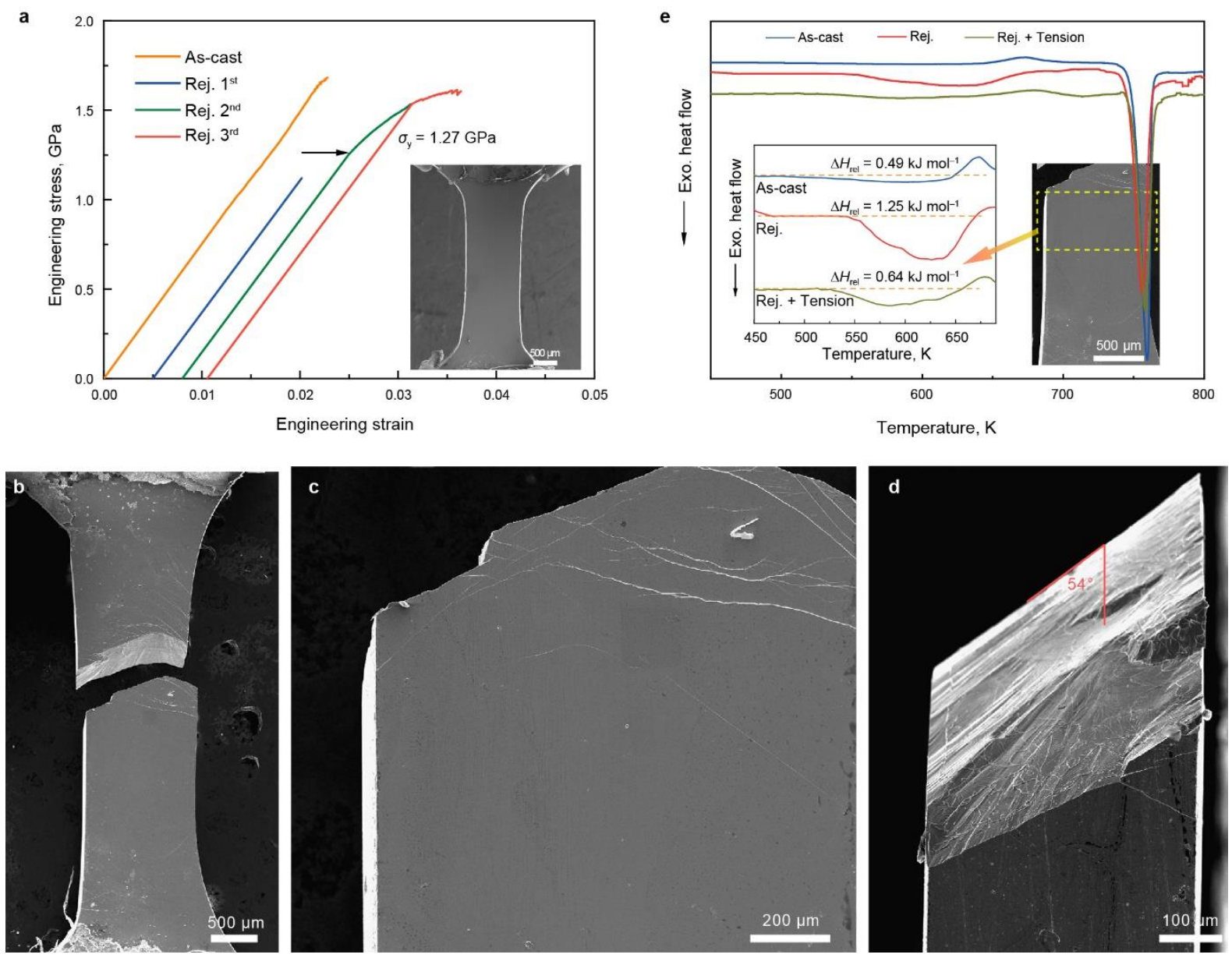

Extended Data Fig. 3 | Tensile testing of rejuvenated Zr64.13Cu15.75Ni10.12Al10 MG. a, The test sample is shown in the inset. The stress-strain curves obtained on reloading are offset for clarity. On the second loading (blue curve), yielding (indicated by the arrow) begins at $\sigma_{\mathrm{y}}=1.27 \mathrm{GPa}$ and $\varepsilon_{\mathrm{y}}=1.7 \%$, and continues to $\varepsilon_{\mathrm{p}}=0.26 \%$ and $\varepsilon_{\mathrm{t}}=2.35 \%$; at that point $\sigma_{\mathrm{f}}=1.52 \mathrm{GPa}$, which is the yield stress at which flow resumes on the third loading, showing clear strain-hardening. On the third loading, serrations begin at $\varepsilon_{\mathrm{p}}=0.31 \%$ and $\varepsilon_{\mathrm{t}}=2.73 \%$, and ultimate failure is at $\varepsilon_{\mathrm{p}}=0.42 \%, \varepsilon_{\mathrm{t}}=2.84 \%$ and $\sigma_{\mathrm{f}}=1.61 \mathrm{GPa} . \mathbf{b}, \mathbf{c}$, Shear-banding is observed only near the fracture. It is clear that shear-banding can be suppressed for small $\varepsilon_{\mathrm{p}}$ and that this suppression is important because the onset of shear-banding appears to be quickly followed by fracture. d, Fracture occurs by shear in the through-thickness direction on a plane inclined at $54^{\circ}$ to the tensile axis. This angle is typical for MG failure in tension ${ }^{40}$. e, Differential scanning calorimetry traces measured on heating MG samples at $20 \mathrm{~K} \mathrm{~min}^{-1}$ : as-cast (blue), rejuvenated (red), and rejuvenated and then deformed to fracture in uniaxial tension (green). The dashed horizontal lines in the inset show the baseline with respect to which the heat of relaxation $\Delta H_{\text {rel }}$ is measured. Details about the samples are provided in 
Extended Data Table 3. The dashed box in the inset shows the portion of the fractured sample used for the DSC measurement of the rejuvenated and deformed MG. In agreement with the results of compression tests (Fig. 1b and Fig. 3), the strain-hardening in tension can also be associated with structural relaxation: the heat of relaxation in the rejuvenated MG, $1.25 \mathrm{~kJ} \mathrm{~mol}^{-1}$, is reduced to $0.64 \mathrm{~kJ} \mathrm{~mol}^{-1}$ in the sample loaded in tension to fracture. Exo., exothermic; Rej., rejuvenated sample; Rej. + Tension, rejuvenated and deformed sample.

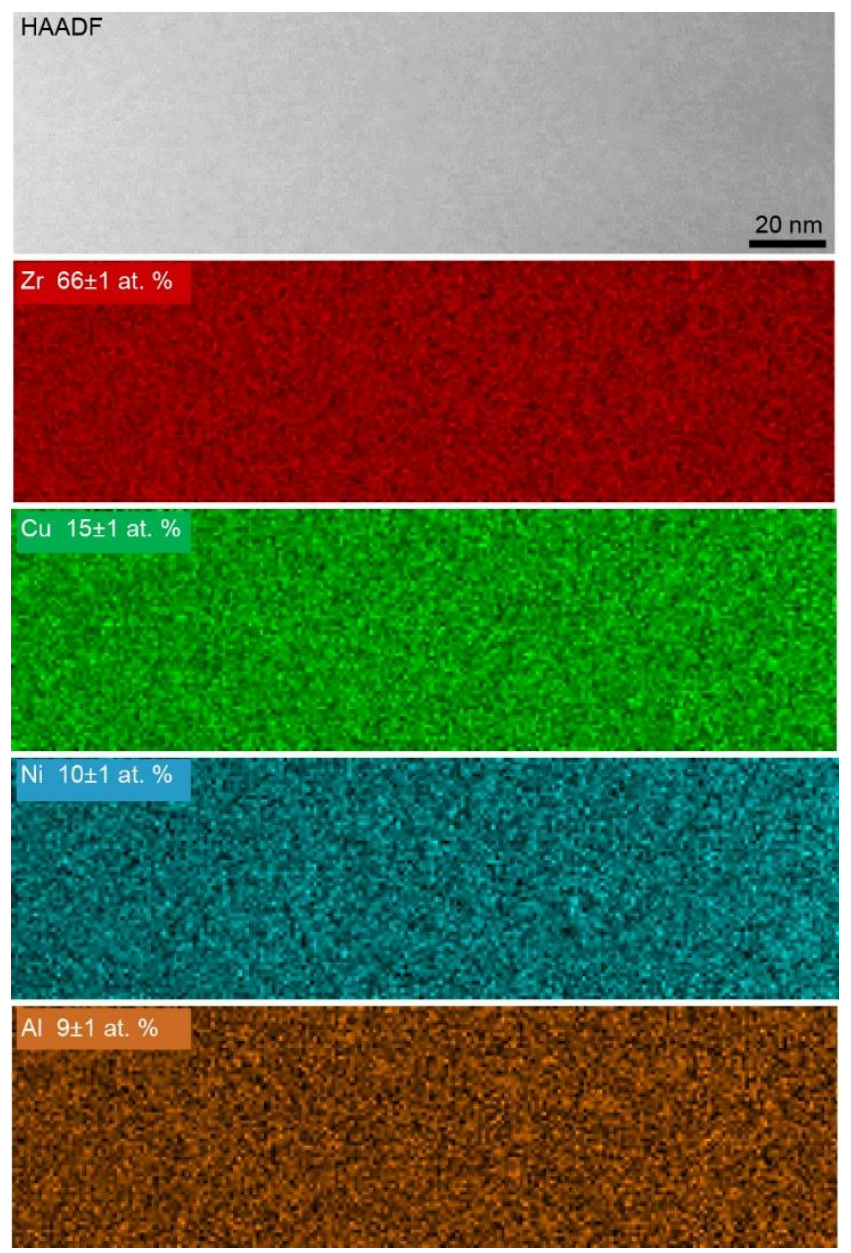

\section{Extended Data Fig. 4 | TEM of the central region of a rejuvenated}

$\mathrm{Zr}_{64.13} \mathrm{Cu}_{15.75} \mathrm{Ni}_{10.12} \mathrm{Al}_{10}$ MG sample. The high-angle annular dark-field (HAADF) image and the EDX maps show the sample to be structurally and chemically homogeneous. The measured elemental contents are close to the nominal values. at. \%, atomic percentage. 

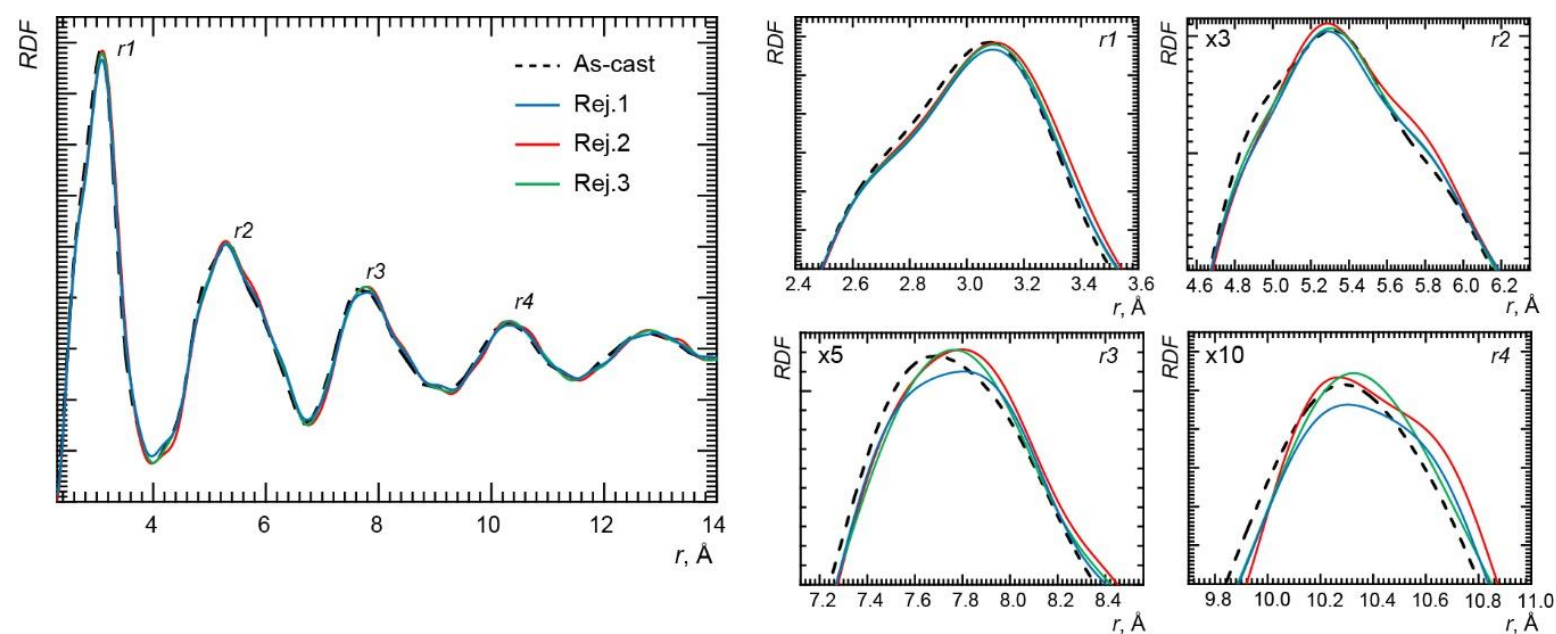

\section{Extended Data Fig. 5 | Radial distribution function analysis of as-cast and rejuvenated} samples of $\mathrm{Zr}_{64.13} \mathrm{Cu}_{15.75} \mathrm{Ni}_{10.12} \mathrm{Al}_{10}$ MG. The radial distribution functions (RDF) are computed from SAED patterns acquired by TEM. The RDF represents the local density of atoms at a distance $r$ from a central atom. The samples are taken from the regions indicated in Fig. $4 b$ (inset). The as-cast sample is taken from a region far from that affected by the rejuvenation treatment. In samples from rejuvenated regions, the nearest-neighbour $(r 1)$ peak is at higher $r$ value than the as-cast sample. Because no change in chemical homogeneity is observed, this shift is taken to indicate a reduction in density of the MG, as also inferred from the first peak in $I(q)$ (Fig. 4b). The second peak ( $r 2)$ shows the splitting (shoulder at high $r$ ) that is characteristic of $\mathrm{MGs}^{41,42}$. This characteristic shape appears on cooling the liquid through the glass transition, and can be taken to indicate the nature of the linking between the nearest-neighbour coordination shells around the atoms ${ }^{17}$, with the main peak being associated with linking through shared edges. On rejuvenation, the shoulder at high $r$ grows, indicating more linking through vertices, and the shoulder at low $r$ shrinks, indicating less linking through shared faces. All these changes are consistent with rejuvenation resulting in more loosely packed or liquid-like regions. The labels $\times 3, \times 5$ and $\times 10$ indicate the magnification factors applied to the intensities of the corresponding peaks in the RDF curves to facilitate visualization and comparison. 


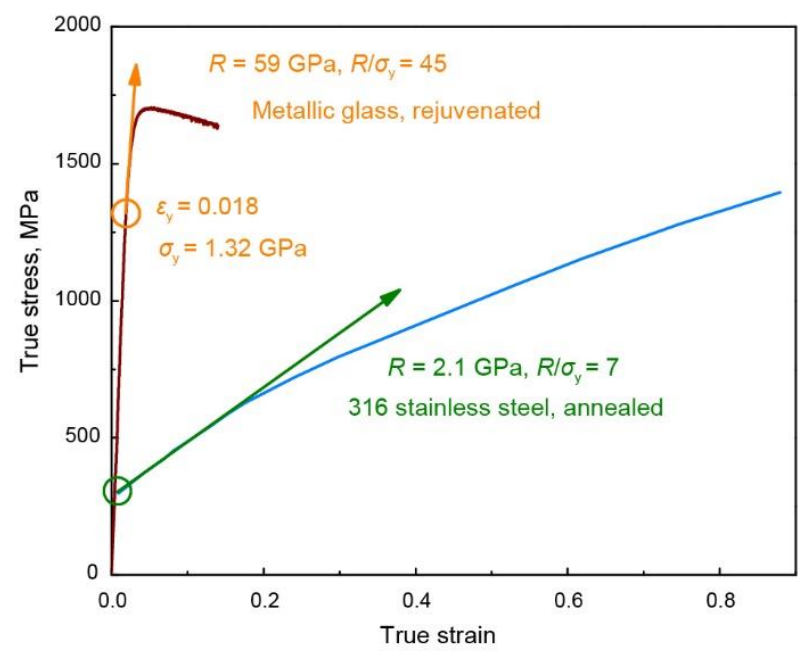

\section{Extended Data Fig. 6 | True stress-true strain curves comparing strain-hardening in} rejuvenated $\mathrm{Zr}_{64.13} \mathrm{Cu}_{15.75} \mathrm{Ni}_{10.12} \mathrm{Al}_{10} \mathrm{MG}$ and in a conventional engineering alloy (316

stainless steel, annealed). The behaviour of crystalline metals and alloys is often characterized by fitting the plastic-flow part of the curve to $\sigma_{\mathrm{f}}=K \varepsilon^{n}$, where $\varepsilon$ is the strain, $K$ is the flow stress at $\varepsilon=1.0$, and the strain-hardening exponent $n$ is typically $0.1-0.3$. Considering the full range of the curve in each case, the elastic limit (circled) occurs at much higher relative stress and strain for the MG than for the conventional alloy, and $n$ is inappropriate for characterizing the MG. Instead we use the initial rate of hardening, $R=\mathrm{d}$ (true stress)/d(true strain), indicated by the arrows. The MG has much higher values of $R$ and of $R / \sigma_{\mathrm{y}}$-so high that, except in close-up (for example, Fig. 1b inset), the transition from elastic to plastic deformation is difficult to discern - and a much smaller total increase in flow stress $\sigma_{\mathrm{f}}$ relative to $\sigma_{\mathrm{y}}$. The high value of $R / \sigma_{\mathrm{y}}$ leads to rapid saturation of the hardening, after which the MG reverts to the strain-softening behaviour of as-cast unrejuvenated glasses. Notably, however, the rejuvenated and then hardened glass continues to have much more uniform flow (smaller stress serrations) than an as-cast glass. The curve for the stainless steel is based on published data ${ }^{43}$, and can be taken as an intermediate case for engineering alloys: the value of $R / \sigma_{\mathrm{y}}$ and the strain to failure is higher for pure metals and lower for hardened alloys. The curve for the MG measured in this work was obtained on continuous loading under compression. 


\begin{tabular}{|c|c|c|}
\hline Sample, composition (at.\%) & Mechanical test & Key results and interpretation as given in the original reference \\
\hline \multicolumn{3}{|l|}{ Effects of small sample size } \\
\hline $\begin{array}{l}\mathrm{Zr}_{52.5} \mathrm{Cu}_{17.9} \mathrm{Al}_{10} \mathrm{Ni}_{14.6} \mathrm{Ti}_{5} \text { bulk, sliced to } \\
45-\mu \mathrm{m} \text {-thick plate and then machined } \\
\text { by focused-ion beam ( } \mathrm{FIB}^{\prime} \mathrm{d} \text { ). }\end{array}$ & $\begin{array}{l}\text { Tension. Cross-section } \\
100 \times 100 \mathrm{~nm}^{2} \text { and } 250 \mathrm{~nm} \\
\text { gauge length. }\end{array}$ & $\begin{array}{l}\text { Demonstration of homogeneous plastic flow in tension, but with } \\
\text { immediate onset of necking in the absence of strain-hardening }{ }^{22} \text {. }\end{array}$ \\
\hline $\begin{array}{l}\mathrm{Zr}_{35} \mathrm{Ti}_{30} \mathrm{Co}_{6} \mathrm{Be}_{29} \text { BMG, FIB'd to } 100 \\
\text { nm diam. }\end{array}$ & $\begin{array}{l}\text { Tension. } 800 \mathrm{~nm} \text { gauge } \\
\text { length. }\end{array}$ & $\begin{array}{l}\text { Homogeneous flow; strain-hardening seen by unloading and reloading; } \\
\text { failure by shear offset }{ }^{10}\end{array}$ \\
\hline $\begin{array}{l}\mathrm{Cu}_{49} \mathrm{Zr}_{51} \text { melt-spun, FIB'd to } 200-300 \\
\text { nm cross-section. }\end{array}$ & $\begin{array}{l}\text { Tension. } 1.2 \mu \mathrm{m} \text { gauge } \\
\text { length. }\end{array}$ & $\begin{array}{l}\text { Apparent strain-hardening seen by unloading and reloading, attributed to } \\
\text { delayed SB nucleation }{ }^{23} \text {. }\end{array}$ \\
\hline $\begin{array}{l}\mathrm{Cu}_{49} \mathrm{Zr}_{51} \text { melt-spun, FIB'd to } 70-120 \\
\text { nm cross-section. }\end{array}$ & $\begin{array}{l}\text { Tension. } 1 \mu \mathrm{m} \text { gauge } \\
\text { length. }\end{array}$ & $\begin{array}{l}\text { Flow is homogeneous, but there is early necking, because there is } \\
\text { limited strain- or strain-rate hardening }{ }^{24} \text {. }\end{array}$ \\
\hline $\begin{array}{l}\mathrm{Ni}_{85.1} \mathrm{P}_{14.9} \text { electroplated pillars, } 70 \mathrm{~nm} \\
\text { and } 100 \mathrm{~nm} \text { diam. } \mathrm{Ni}_{86} \mathrm{P}_{14} \\
\text { electroplated, FIB'd to } 100 \mathrm{~nm} \text { diam. }\end{array}$ & $\begin{array}{l}\text { Tension. Gauge lengths } \\
430-630 \mathrm{~nm} \text {. }\end{array}$ & $\begin{array}{l}\text { Strain-hardening attributed to reduction of free volume associated with } \\
\text { surface relaxation }{ }^{25} \text {. }\end{array}$ \\
\hline \multicolumn{3}{|l|}{ Triaxial constraint } \\
\hline $\begin{array}{l}\mathrm{Zr}_{64.13} \mathrm{Cu}_{15.75} \mathrm{Ni}_{10.12} \\
\mathrm{Al}_{10} \text { rod, } 5 \mathrm{~mm} \text { diam. }\end{array}$ & Tension. Notched rod. & $\begin{array}{l}\text { Increased hardness and lower enthalpy after plastic deformation, } \\
\text { attributed to acceleration of free-volume annihilation under constraint } \\
\text { with high triaxial tension }{ }^{11} \text {. }\end{array}$ \\
\hline \multicolumn{3}{|l|}{ Effects just beyond the elastic limit, $\varepsilon_{\theta}$} \\
\hline Review of many systems. & Uniaxial compression. & $\begin{array}{l}\text { Ratio of } \varepsilon_{\mathrm{e}} \text { to macroscopic yield stress } \varepsilon_{\mathrm{y}}, \varepsilon_{\mathrm{e}} / \varepsilon_{\mathrm{y}}=0.77-0.99 \text {; this } \\
\text { hardening is attributed progressive interaction of } \mathrm{SBs}^{26} \text {. }\end{array}$ \\
\hline \multicolumn{3}{|l|}{ Single dominant shear band } \\
\hline $\mathrm{Zr}_{50} \mathrm{Cu}_{44} \mathrm{Al}_{6}$ rod, $2 \mathrm{~mm}$ diam. & $\begin{array}{l}\text { Uniaxial compression. } \\
\text { Rods } 4 \mathrm{~mm} \text { long. }\end{array}$ & $\begin{array}{l}\text { Hardening is attributed to melting and resolidification of the dominant SB } \\
\text { under pressure }{ }^{27} \text {. }\end{array}$ \\
\hline \multicolumn{3}{|l|}{ High-pressure torsion (HPT, 30 turns) } \\
\hline $\mathrm{Zr}_{65} \mathrm{Al}_{7.5} \mathrm{Ni}_{10} \mathrm{Cu}_{12.5}$ & Tension. Cross-section & High-density of SBs induced by HPT induces multiplication of SBs during \\
\hline $\mathrm{Pd}_{5}$ rod, $8 \mathrm{~mm}$ diam., cut to & $0.7 \times 1.0 \mathrm{~mm}^{2}$ and gauge & tension ${ }^{28} ;$ also there is constraint due to the short gauge length. \\
\hline 1.5-mm-thick disc, then HPT. & length $1.25 \mathrm{~mm}$. & \\
\hline
\end{tabular}

\section{Extended Data Table 1 | Apparent strain-hardening in monolithic MGs}

There are several reports in the literature of what has usually been termed 'apparent' strain-hardening in single-phase MGs. Key observations ${ }^{10,11,22-28}$ (all at room temperature) listed in the table are grouped according to the main factor leading to the apparent hardening. Some of the proposed mechanisms involve shear bands (SBs); here, however, we argue that the presence of SBs is incompatible with true strain-hardening, because the formation of bands is intrinsically a manifestation of strain-softening. If we exclude the cases in which the proposed hardening involves the operation of SBs, then strain-hardening is seen only when associated with a small sample size or with triaxial constraint of the deformed specimen. diam., diameter. 


\begin{tabular}{|c|c|c|}
\hline Sample, composition (at.\%) & Mechanical test & Key results and interpretation as given in the original reference \\
\hline \multicolumn{3}{|l|}{ Effects of a dispersed second phase } \\
\hline $\begin{array}{l}\mathrm{Cu}_{47.5} \mathrm{Zr}_{47.5} \mathrm{Al}_{5} \\
\text { rod, } 2 \mathrm{~mm} \text { diam. }\end{array}$ & $\begin{array}{l}\text { Uniaxial compression. Rods } 4 \\
\text { mm long. }\end{array}$ & $\begin{array}{l}\text { Sub-nm heterogeneities lead to a high density of SBs; strain-hardening } \\
\text { is attributed to the interaction of SBs hindering their rapid propagation }{ }^{29} \text {. }\end{array}$ \\
\hline $\begin{array}{l}\mathrm{Fe}_{40} \mathrm{Ni}_{40} \mathrm{P}_{14} \mathrm{~B}_{6} \\
\text { rod, } 1.6 \mathrm{~mm} \text { diam. }\end{array}$ & $\begin{array}{l}\text { Uniaxial compression, Rods } \\
3.2 \mathrm{~mm} \text { long. }\end{array}$ & $\begin{array}{l}\text { High density of SBs, due to nanoscale phase separation favouring SB } \\
\text { nucleation and hindering SB propagation }{ }^{30} \text {. }\end{array}$ \\
\hline $\begin{array}{l}\mathrm{Zr}_{63.78} \mathrm{Cu}_{14.72} \mathrm{Ni}_{10-x} \mathrm{Co}_{x} \mathrm{Al}_{10} \mathrm{Nb}_{1.5} \\
\text { rod, } 2 \mathrm{~mm} \text { diam. }\end{array}$ & $\begin{array}{l}\text { Uniaxial compression. Rods } 4 \\
\text { mm long. }\end{array}$ & $\begin{array}{l}\text { High density of SBs, due to nanoscale phase separation favouring SB } \\
\text { nucleation and hindering SB propagation; also secondary phase } \\
\text { separation induced near SBs }{ }^{31} \text {. }\end{array}$ \\
\hline $\begin{array}{l}\mathrm{Zr}_{57.75-x} \mathrm{Cu}_{21.15} \mathrm{Fe}_{4.7} \\
\mathrm{Al}_{9.4} \mathrm{Nb}_{6} \mathrm{Co}_{x} \mathrm{Mo}_{1} \text { rod, } 2 \mathrm{~mm} \text { diam. }\end{array}$ & $\begin{array}{l}\text { Uniaxial compression. Rods } 4 \\
\text { mm long. }\end{array}$ & $\begin{array}{l}\text { High density of SBs, and two-stage strain-hardening associated with } \\
\text { phase separation and nanocrystallization induced near the } \mathrm{SBs}^{32} \text {. }\end{array}$ \\
\hline $\begin{array}{l}\left(\mathrm{Cu}_{47} \mathrm{Zr}_{47} \mathrm{Al}_{6}\right)_{99} \mathrm{Sn}_{1} \text { rod, } 2 \mathrm{~mm} \\
\text { diam. }\end{array}$ & $\begin{array}{l}\text { Uniaxial compression. Rods } 4 \\
\text { mm long. }\end{array}$ & $\begin{array}{l}\text { Nanoscale phase separation leads to a high density of SBs; } \\
\text { strain-hardening is attributed to the interaction of SBs hindering their } \\
\text { rapid propagation }{ }^{33} \text {. }\end{array}$ \\
\hline \multicolumn{3}{|c|}{ Plasticity resulting from transformation of a second phase } \\
\hline $\begin{array}{l}\mathrm{Zr}_{48} \mathrm{Cu}_{47.5} \mathrm{Co}_{0.5} \mathrm{Al}_{4} \text { rod, } 3 \mathrm{~mm} \\
\text { diam., } 25 \% \text { volume fraction of } \mathrm{B} 2 \\
\mathrm{CuZr}(100 \mu \mathrm{m} \& 30 \mathrm{~nm} \text { diam. }) \text { in } \\
\text { a glassy matrix. }\end{array}$ & $\begin{array}{l}\text { Tension. Cross-section } 1.5 \mathrm{~mm} \\
\text { diam. and gauge length } 6 \mathrm{~mm} \text {. }\end{array}$ & $\begin{array}{l}\text { Plastic flow induces softening of the glassy matrix, and hardening of the } \\
\text { CuZr crystals through martensitic transformation of B2 to B19'. Overall, } \\
\text { there is significant strain-hardening }{ }^{34,35} \text {. }\end{array}$ \\
\hline $\begin{array}{l}\mathrm{Cu}_{47.5} \mathrm{Zr}_{47.5} \mathrm{Al}_{5} \text {, plate, } 1.5 \times 10 \times 60 \\
\mathrm{~mm}^{3}\end{array}$ & $\begin{array}{l}\text { Tension. Cross-section } 1.5 \times 2 \\
\mathrm{~mm}^{2} \text { and gauge length } 40 \mathrm{~mm} \text {. }\end{array}$ & $\begin{array}{l}\text { Plastic flow induces formation of } 10-50 \mathrm{~nm} \text { crystals of } \mathrm{B} 2 \mathrm{CuZr} \text { and their } \\
\text { subsequent twinning. SB generation is hindered by the polymorphic } \\
\text { crystallization and twinning, both attributed to flow-induced reduction in } \\
\text { shear modulus }^{35,36} \text {. }\end{array}$ \\
\hline $\begin{array}{l}\mathrm{Ti}_{48} \mathrm{Zr}_{27} \mathrm{Ni}_{6} \mathrm{Be}_{14} \mathrm{Ta}_{5} \text { bulk, } \\
\text { processed to have dendrites } \\
\text { (trunk diam. } \approx 15 \mu \mathrm{m} \text { ) of } \beta \text {-phase } \\
\text { in a glassy matrix. }\end{array}$ & $\begin{array}{l}\text { Tension. Cross-section } 1 \times 2 \\
\mathrm{~mm}^{2} \text { and gauge length } 12 \mathrm{~mm} \text {. }\end{array}$ & $\begin{array}{l}\text { Elastic loading starts the } \beta \text {-to- } \alpha^{\prime} \text { martensitic transformation. Plastic flow } \\
\text { induces further transformation and twinning of the } \alpha^{\prime} \text { that is formed, } \\
\text { giving strain-hardening that delays necking and permits a plastic } \\
\text { elongation of } 9.5 \%{ }^{37} \text {. }\end{array}$ \\
\hline $\begin{array}{l}\mathrm{Cu}_{47.5} \mathrm{Zr}_{47.5} \mathrm{Al}_{5} \text { rod, } 2 \text { or } 3 \mathrm{~mm} \\
\text { diam., with controlled cooling to } \\
\text { give a dispersion of } \mathrm{B} 2 \text { and } \mathrm{B}_{19} \\
\text { phases in a residual glassy } \\
\text { matrix of } 19.5 \% \text { volume fraction. }\end{array}$ & $\begin{array}{l}\text { Uniaxial compression. Rods of } \\
2: 1 \text { aspect ratio (height:diam.). }\end{array}$ & $\begin{array}{l}\text { Flow is in stages: (i) deformation of the B2 CuZr phase starts its } \\
\text { martensitic transformation to B19', (ii) further transformation and multiple } \\
\text { SBs in the glassy matrix, (iii) dislocation multiplication and detwinning in } \\
\text { the B19' phase. The result is significant strain-hardening leading to a } \\
\text { plastic elongation of } 13.5 \%^{38} \text {. }\end{array}$ \\
\hline
\end{tabular}

\section{Extended Data Table 2 | Strain-hardening in MG-matrix composites}

A dispersion of a second phase in an MG matrix must affect the operation of SBs in an MG, but in the same way as for monolithic MGs (Extended Data Table 1) we consider any SB activity to be incompatible with true strain-hardening of the MG. Key observations ${ }^{29-38}$ (all at room temperature) are listed in the table. Strain-hardening of composites in tension is clearly associated with transformationinduced hardening of a dispersed crystalline phase that is sufficient to outweigh the softening of the MG matrix. 


\begin{tabular}{|c|c|c|c|c|}
\hline Sample & $\sigma_{\mathrm{y}}$ or $\sigma_{\mathrm{f}}(\mathrm{GPa})^{*}$ & $\Delta H_{\text {rel }}\left(\mathrm{kJ} \mathrm{mol}^{-1}\right)$ & $H v\left(k g f m^{-2}\right)$ & $q_{1}\left(\mathrm{~A}^{-1}\right)$ \\
\hline \multicolumn{5}{|l|}{$\mathrm{Zr}_{64.13} \mathrm{Cu}_{15.75} \mathrm{Ni}_{10.12} \mathrm{Al}_{10}$} \\
\hline \multicolumn{5}{|c|}{ All data in the main text are for this composition, for which extreme rejuvenation was first demonstrated ${ }^{13}$. } \\
\hline as-cast rod, $2 \mathrm{~mm}$ diam. & $\sigma_{y}=-1.70 \pm 0.06$ & $0.49 \pm 0.04$ & $495 \pm 5$ & $2.564 \pm 0.004^{\dagger}$ \\
\hline unnotched rod, compressed to $\varepsilon_{p}=-40 \%$ & & $0.65 \pm 0.05$ & $465 \pm 12$ & \\
\hline rejuvenated & $\sigma_{y}=-1.35 \pm 0.07$ & $1.08 \pm 0.06$ & $421 \pm 9$ & $2.538 \pm 0.004^{\ddagger}$ \\
\hline rejuvenated, compressed to $\varepsilon_{\mathrm{p}}=-1.0 \%$, & $\sigma_{\mathrm{y}}=-1.44 \pm 0.09$ & $0.71 \pm 0.05$ & $451 \pm 10$ & \\
\hline \multicolumn{5}{|l|}{$\varepsilon=-3.2 \%{ }^{5}$, then $\sigma_{y}$ measured } \\
\hline compressed to $\varepsilon_{\mathrm{p}}=-1.9 \%, \varepsilon_{\mathrm{t}}=-4.5 \%$ & $\sigma_{y}=-1.32 \pm 0.05$ & $0.67 \pm 0.05$ & $461 \pm 9$ & \\
\hline compressed to $\varepsilon_{\mathrm{p}}=-3.5 \%, \varepsilon_{\mathrm{t}}=-6.1 \%$ & $\sigma_{y}=-1.34 \pm 0.06$ & $0.65 \pm 0.03$ & $464 \pm 15$ & \\
\hline compressed to $\varepsilon_{\mathrm{p}}=-22.5 \%, \varepsilon_{\mathrm{t}}=-25.6 \%$ & $\sigma_{y}=-1.43 \pm 0.05$ & $0.79 \pm 0.06$ & $451 \pm 10$ & \\
\hline compressed to $\varepsilon_{\mathrm{p}}=-0.57 \%, \varepsilon_{\mathrm{t}}=-2.9 \%$ & & & & $2.551 \pm 0.004$ \\
\hline compressed to $\varepsilon_{\mathrm{p}}=-0.93 \%, \varepsilon_{\mathrm{t}}=-3.2 \%$ & & & & $2.553 \pm 0.004$ \\
\hline as-cast rod, $5 \mathrm{~mm}$ diam. & $\sigma_{\mathrm{y}}=+1.66 \pm 0.06$ & $0.50 \pm 0.04$ & & \\
\hline rejuvenated & $\sigma_{\mathrm{y}}=+1.27 \pm 0.07$ & $1.25 \pm 0.10$ & & \\
\hline tension to $\varepsilon_{\mathrm{p}}=0.68 \%, \varepsilon_{\mathrm{t}}=2.84 \%$ & $\sigma_{\mathrm{y}}=+1.27 \pm 0.07$ & $0.72 \pm 0.05$ & & \\
\hline tension to $\varepsilon_{\mathrm{p}}=0.90 \%, \varepsilon_{\mathrm{t}}=3.03 \%$ & $\sigma_{y}=+1.30$ & $0.64 \pm 0.06$ & & \\
\hline \multicolumn{5}{|l|}{$\mathrm{Zr}_{61} \mathrm{Cu}_{25} \mathrm{Al}_{12} \mathrm{Ti}_{2}$} \\
\hline \multicolumn{5}{|c|}{ This composition has a better glass-forming ability than the previous MG. The maximum diameter to be fully glassy is $\sim 10 \mathrm{~mm}^{39}$. } \\
\hline as-cast rod, $1.5 \mathrm{~mm}$ diam. & $\sigma_{y}=-1.65 \pm 0.05$ & & & \\
\hline rejuvenated & $\sigma_{y}=-1.37 \pm 0.07$ & & & \\
\hline rejuvenated, then $\sigma_{\mathrm{f}}$ measured at & $\sigma_{\mathrm{f}}=-1.51 \pm 0.02$ & & & \\
\hline \multicolumn{5}{|l|}{ compressive strain $\varepsilon_{\mathrm{p}}=-0.1 \%, \varepsilon_{\mathrm{t}}=-1.8 \%$} \\
\hline at $\varepsilon_{\mathrm{p}}=-0.24 \%, \varepsilon_{\mathrm{t}}=-2.1 \%$ & $\sigma_{\mathrm{f}}=-1.66 \pm 0.02$ & & & \\
\hline at $\varepsilon_{\mathrm{p}}=-0.8 \%, \varepsilon_{\mathrm{t}}=-2.8 \%$ & $\sigma_{\mathrm{f}}=-1.87 \pm 0.02$ & & & \\
\hline at $\varepsilon_{\mathrm{p}}=-1.5 \%, \varepsilon_{\mathrm{t}}=-3.7 \%$ & $\sigma_{f}=-1.96 \pm 0.02$ & & & \\
\hline at $\varepsilon_{\mathrm{p}}=-3.0 \%, \varepsilon_{\mathrm{t}}=-5.3 \%$ & $\sigma_{\mathrm{f}}=-2.02 \pm 0.02$ & & & \\
\hline at $\varepsilon_{\mathrm{p}}=-17.4 \%, \varepsilon_{\mathrm{t}}=-20 \%$ & $\sigma_{\mathrm{f}}=-2.41 \pm 0.02$ & & & \\
\hline
\end{tabular}

Extended Data Table 3 | Values of yield stress $\sigma_{y}$, flow stress $\sigma_{f}$, microhardness $\mathrm{Hv}$, heat of relaxation $\Delta H_{\text {rel }}$ and main halo position $q_{1}$ for samples of two bulk MGs

The second composition, $\mathrm{Zr}_{61} \mathrm{Cu}_{25} \mathrm{Al}_{12} \mathrm{Ti}_{2}$, has the better glass-forming ability ${ }^{39}$.

*Negative (positive) values denote measurement under compression (tension). 
†Measured on a 4-mm-diameter rod at the location shown schematically in red in the inset in Fig. 4b. †The value is the same, within measurement error, for all three locations (red, blue, green) shown in the inset in Fig. 4b.

sPlastic strain $\left(\varepsilon_{p}\right)$ and total strain $\left(\varepsilon_{t}\right)$. 